\title{
Thinking through the non-native language: The role of private speech in mediating cognitive functioning in problem solving among proficient non-native speakers
}

\author{
Mostafa M. Garbaj
}

\begin{abstract}
Extending Vygotsky's theory and research to non-native language speakers, the literature available to date has provided inconclusive findings on whether L2 speakers use the non-native language to mediate thinking in problem solving. Avoiding limitations in previous studies, the present study investigated private speech produced by non-native speakers with the objective of discovering whether the non-native language can be effectively used as a medium for thinking just as the L1. Non-technical highly challenging multi-level problem-solving activity was utilized to collect private speech from four native speakers and seven L2 speakers of English. Data analysis focused on examining the characteristics of private speech in order to assess cognitive mediation in the L2. The results provided strong evidence that proficient speakers - with extensive formal and informal language acquisition experiences - used the non-native language to mediate their thinking and, unlike in previous research, there was no reversion to the $L 1$.
\end{abstract}

KEYWORDS: PRIVATE SPEECH; NON-NATIVE LANGUAGE; SOCIOCULTURAL THEORY; COGNITIVE FUNCTIONING L2; PROBLEM SOLVING

\section{Introduction}

Guided by Vygotsky's sociocultural theory, the present study attempts to advance our understanding of the use of non-native language in mediating

\footnotetext{
$\overline{\text { Affiliation }}$

Asmarya University, Libya.

email: garbajm@gmail.com
} 
mental functioning in problem solving. The study specifically seeks to answer the question of whether or not highly proficient non-native speakers use L2 private speech to mediate their thinking in problem solving as is the case with the L1.

Vygotsky argued that language mediates and regulates a person's social (interpersonal) and mental (intrapersonal) activity (Lantolf and Thorne, 2006). Vygotsky (1978) proposed that language mediation for the self originates from the social context when children begin to use social speech in the form of egocentric speech, which eventually becomes silent and converts into inner speech as the child matures. In the face of difficult tasks, inner speech resurfaces as audible speech, which is referred to as private speech, in order to overcome the difficulty and regain self-regulation.

Private speech is called private not because it is produced in privacy, but because it is meant to assist the mental functioning of the person who produced it. Vygotsky underscored the importance of private speech and, contrary to what had been previously believed (e.g., Piaget, 1959), he claimed that the act of speaking when performing a task is an integral part of the reasoning process. Private speech is psychologically oriented and serves to 'regulate the mental activity of the individual in the execution of a cognitive or physical task ...' (Lantolf and Thorne, 2006: 76). This connection between private speech and mental regulation is valuable because 'analysis of ... private speech brings to the surface aspects of the strategic functioning of the human mind that might otherwise remain covert' (Lantolf, DiCamilla, and Ahmed, 1997: 157). The link between cognition and language represented a point of departure for many researchers to further investigate the use of self-directed speech to assist cognitive functioning. The importance of private speech is then derived from the fact that it provides a window on the inner states of the mind (Lantolf and Thorne, 2006). In describing the role language has in mediating thinking, Vygotsky states that 'thought ... realizes itself in [words]' (1986: 251).

Given this unique nature of private speech, it has been targeted by many researchers in the sociocultural paradigm. One active area of research on private speech has focused on understanding the nature and depth of the cognitive function of non-native private speech. A number of researchers (e.g., Ahmed, 1994; Centeno-Cortés and Jimenéz-Jimenéz, 2004; Frawley and Lantolf, 1985) have attempted to examine whether self-directed speech plays the same cognitive function for L2 speakers as it does for L1 speakers. The studies available utilized either story-telling tasks (e.g., Frawley and Lantolf, 1985; McCafferty, 1994) or challenging problem and solving activities (e.g., Centeno-Cortés and Jiménez-Jiménez, 2004) to investigate mental functioning in L2. These studies have enhanced our understanding of the cognitive

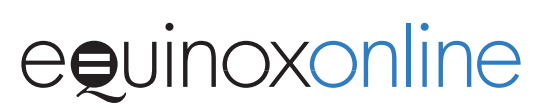


functioning of private speech in a non-native language; however, they have provided inconclusive findings on this matter (for more details on this issue, see Lantolf and Thorne, 2006: 83-94).

Studies that used problem-solving activities to elicit private speech and investigate cognitive functioning in L2 have focused on a factor that could be labelled as shift in language (studies that used online narratives focused on other factors such as tense use and amount of private speech and are not discussed here). Shift in language basically means whether or not L2 speakers utilize their L2 consistently throughout a problem-solving activity without shifting to the L1. Generally, failure to maintain use of the L2 for selfregulation throughout a given task - by switching to the L1- was interpreted as the speaker's inability to use the L2 as an effective mediator for mental functioning. Centeno-Cortés and Jiménez-Jiménez (2004) conducted an investigation in which they relied mainly on the factor of language shift in deciding whether or not non-native speakers could mediate their mental functioning in problem-solving tasks. The most significant result from this study, as the researchers reported, was that although advanced speakers used L2 private speech as they worked on the problems, they resorted to their L1 as the task became too challenging. The researchers stated that '.. this finding is consistent with Ushakova (1994) [who holds the extreme view that no language beyond the L1 can mediate thought], since it shows that very often the L1 surfaces in the private speech of L2 learners' (31).

Although Centeno-Cortés and Jiménez-Jiménez's study employed a unique methodology in order to closely investigate the use of L2 private speech in mediating cognition, there are two concerns that we cannot overlook when interpreting the findings of this particular study. The first is that the study did not use highly proficient L2 speakers; the researchers stated that none of their advanced speakers had more than a year of informal exposure to the second language. In SCT research, informal exposure was reported to be an important factor in speeding up self-regulation in an L2 (cf. Lantolf and Frawley, 1994: 121). The second concern is that the study employed mathematical problems, which may have a special nature and are different from average cognitive and verbal tasks. This view about the special nature of mathematical problems was reported in an experiment by Spelke and Tsivkin (2001), who found that proficient bilingual speakers solved mathematical problems more effectively in the language of training - regardless of whether it is an L1 or L2. Furthermore, in a more recent study, Jiménez-Jiménez (2015: 16) argued that '... meaning is intimately linked to the language in which that meaning was initially created ...' This means that the language we use to acquire a piece of knowledge may be the preferred language when we revisit that type of knowledge. In other words, the mind processes information better in the language of acquisition

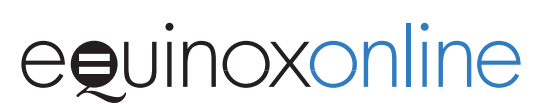


when working on technical non-generic problems. Problems related to mathematical operations and the kinship system belong to non-generic types of knowledge that involve special processes, terminologies and patterns.

Another study that indicated a shift to the mother tongue in the course of thinking in problem solving was conducted by Cohen (1994). This investigation, which focused on language preference in doing math problems and used learners of Spanish selected from the fifth and sixth grades in a full immersion school, used classroom observation and self-reports to collect data. Although Cohen's study was not framed within sociocultural theory and targeted younger learners, part of the data involved private speech collection since the participants were recorded while they were talking to themselves as they worked on the problems. Analysis of the data indicated that although the participants started speaking in the L2 when they approached the problems, they switched to the $\mathrm{L} 1$ at some point as the problem became more difficult, a result that was similar to Centeno-Cortés and Jiménez-Jiménez’s (2004) observation.

Thus, such technical problems may not be the best choice to measure general cognitive functioning. It seems that in order to obtain reliable results on assessing the use of L2 private speech in mediating cognitive functioning, we need to exclude problems that require special or technical knowledge to be resolved. This is specifically true in the case of late bilinguals (as those used in Centeno-Cortés and Jiménez-Jiménez, 2004) whose mathematical knowledge is framed in the L1; thus, the participants would be more likely to rely on the L1 when they attempt to operate with that type knowledge.

In light of this discussion, an improved course of investigation on the use of L2 private speech as a cognitive tool in problem solving should pay particular attention to two issues. First, we would not expect late bilinguals who acquired the number system and mathematical knowledge in the native language to use the non-native language effectively when they work on problems related to such a system. Therefore, in order to obtain a clearer picture on the use of L2 private speech in mediating the thinking process it is imperative to use generic non-technical problems that do not require special knowledge or skills. Second, this population of speakers should include individuals with extensive exposure to the L2 in a natural social context. Vygotsky and other scholars (e.g., Lantolf and Frawley, 1994; Vocate, 1994; Vygotsky, 1978) believe that language mediation for the self originates from the social context; that is, private speech is a result of exposure to, and use of, social speech. The present study, then, attempts to answer the question of whether or not highly proficient L2 speakers - with extensive formal (i.e., classroom) and informal learning experiences - use L2 private speech to mediate their thinking in problem solving by applying the following research methodology that takes as its point of departure the two issues mentioned here.

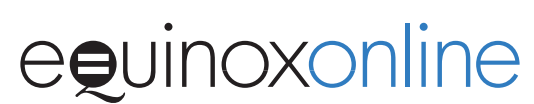




\section{Method}

\section{Participants}

A total of 11 adult speakers participated in the research project: four adult native English speakers and seven adult highly proficient non-native English speakers. The inclusion of the native speakers was important for obtaining baseline data necessary for understanding the non-native speakers' private speech use. In order to avoid the proficiency limitations in previous investigations, the minimum inclusion criteria for the non-native speakers were four years of formal learning and four years of exposure to natural language use. After initial screening based on the minimum period of exposure to the L2, an oral proficiency interview was conducted with each non-native speaker in order to ensure a high level of oral proficiency. Two examiners independently rated each participant's performance on a scale of 1-10 with five points assigned for fluency and five for accuracy. The individual ratings were then averaged to obtain a final proficiency score. Candidates who scored 6.5 or below were excluded from the study (for additional details about each participant, see Appendix 2).

\section{Activity and procedure}

The problem-solving activity used in the study was a non-technical, but highly engaging, and cognitively challenging, logic problem. It was used because it did not involve atypical techniques or concepts; nor did it require a specific type of experience. In order to increase engagement in the task, collect more private speech data and have a better understanding of each participant's performance, the problem-solving activity consisted of three stages with increasing difficulty as the participant moved from one stage to the next.

In the problem, a man, a girl, a boy, a dog and a rabbit need to cross a river on a small boat that can carry no more than two items of cargo at a time. The man should always be with the dog, otherwise it attacks whomever is nearby. The boy should not leave the rabbit near the girl, otherwise she teases it. None of the animals can operate the boat, and there is no limit on the number of times they can use the boat to cross the river. A second rabbit is included with the boy in the next level of complexity; and a cat, which the girl is not supposed to leave near the boy or else he teases it, is included in the third level of complexity. The participants moved the characters represented by small cubes with coloured faces on them across the river - depicted on a sheet of paper - in a little toy vehicle representing the boat. The participants worked on the problem individually. The problem was adapted from its original version available on the internet (Smart-kit: river crossing puzzle, 2012).

The puzzle task was based on a similar task employed in Ahmed's (1994) investigation. However, unlike in the present study, Ahmed's participants

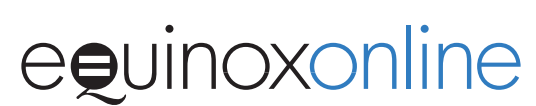


worked in pairs using scrambled pictures, which they had to arrange in the appropriate sequence. To repeat, in the current study each participant was asked to solve the problem individually and over three levels of increasing complexity. All the sessions were audio-recorded. It is worth noting that the task was presented in English; however, the participants were not required to use English. It was left to their discretion if they opted to use their native language. The researcher was present as a non-participant observer whose role was to remind the participants in case they violated the task rules (e.g., transporting three items at a time or making an animal pilot the boat) and to provide assistance with technical and logistic issues when needed.

\section{Analysis}

Vygotsky and his followers argued that inner speech is the hidden voice of the human mind that resurfaces as private speech and becomes audible and available for observation at times of cognitive stress (Lantolf and Thorne, 2006; Vygotsky, 1978). Private speech assists and mediates thinking and it is the observable realization of hidden mental functioning. Vygotsky explained how thinking is unveiled through language: 'thought does not express itself in words, but rather realizes itself in them' (1986: 251). Thus, the project conducted a qualitative examination of the participants' discourse in order to evaluate whether or not it represented language for thought that shares the well-known formal characteristics of private speech. Additionally, other elements like reversion to the L1 and progress in solving the task were also considered in evaluating the participants' use of L2 private speech as an effective cognitive tool. In order to answer the main research question, the analysis attempted to answer the following sub-questions: Were the participants engaged in deep cognitive activity as they worked on each problem? Did they make progress in solving a given problem? Did the participants use the native language at any point in their reasoning?

\section{Characteristics of private speech as a cognitive tool}

The features that were included in the analysis are those that define the discourses as language for cognitive mediation. These features were predominant in the discourse of the participants; and, in comparison, social speech was limited to occasional questions that were addressed to the researcher about the rules of the problem task. The features that are presented here are: Unfinished utterances; reduced utterances; reduced volume and/or whisper; no expectation of response; directions to the self; dialogue with the self; others (sounds, cursing, unintelligible). The utterances were transcribed according to the transcription key included in Appendix 1.

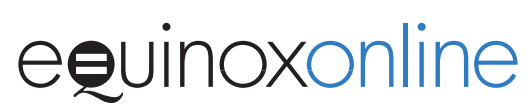




\section{Unfinished utterances}

There were many examples of fragmented or unfinished utterances in both the native as well as the non-native speakers' discourse. It should be made clear that this feature describes situations in which the speaker terminates what he/ she is saying and either goes silent or starts something completely new, which would be rather bizarre in social speech. What follows an unfinished utterance should not be an act of rephrasing but an introduction of something new. The following are examples produced by the native speakers:

NS-1) Ok so maybe the m,, so the g oops the girl drives the boat> over with the man... and then she gets out she's ok cuz.. and then he goes back and gets the bunny.

NS-2) I'm > going $>$ to take, the >, I'm going to take, ah darn it,, [laughs].

NS-3) ...let's see> so what if we ahh what if we had so then he's got to be with him ... I'm gonna get this let's see, $\mathrm{xxx}$ alright this is how we're gonna do it we're gonna, she's useless she can't sail anybody over...

In the first example, the participant terminated her audible reasoning and she either finished her reasoning sub-vocally or started pondering another move because she already knew the rest of what she was thinking (i.e., what came after $\mathrm{cuz}$ ) and did not need to overtly articulate it. In the second example, however, the process of reasoning was terminated with a failure, which was obvious from how the participant ended it with a mild expletive. The hesitation, very quiet voice and frustration make it evident that this participant was deeply involved in communicating with herself in attempting to gain selfregulation. The first excerpt in the third example shows that the reasoning was completed internally and then the participant built on that and re-started the planning process using $s o$ : '... if we had so then ...' In the second excerpt the line of reasoning was either continued covertly or terminated as the speaker said 'we're gonna, she's useless ...' The following examples are from the nonnative speakers' private speech:

NNS-1) ... drop the two rabbits they're safe bring this back ah> then>> , the boy and the girl can go, drop the boy and the girl, $\ldots$

NNS-2) ... that should be the first move take the cat drop the cat come back for, no,

NNS-3) I think the first step should be dropping off the cat,, Xxx no the bunny ....

NNS-4) ... this is I know its gonna okay xx man and dog go xxx girl comes back the $\operatorname{girl} \ldots$ 
The participant in the first example hesitated and went silent for a while after the adverb then, which shows that his audible speech was terminated and he either continued the reasoning silently or failed and started over. In the second example, the audible but quiet reasoning included a long silence and very possibly continued silently. At that time, the speaker was considering which item to take next and then whatever that item was it was rejected as signalled by the word no. The third example is similar to the second in that the participant went silent for a period of time, then her private speech became very quiet and unintelligible and ended with a positive decision to take the bunny. In the fourth example the speaker was murmuring and then ended where he was going and said okay to himself after which he restarted working on the task. These examples indicate that the speakers were not attempting to provide comprehensible speech to outside listeners and that their discourse was meant to assist cognition.

\section{Reduced utterances}

These were also ubiquitous among both groups. As the literature indicated, private speech is usually condensed and abbreviated because the speaker is addressing him/herself and does not need to externalize full structures to make sense of his/her thought. The following are examples produced by the native speakers:

NS-4) I'll take and I'll leave the dog and will the man will come back, and> the boy can't ...

NS-5) ... see you take the girl first, $\mathrm{xxx}$ take this guy first boom, boom, no he can't you have to take the girl first ...

NS-6) ... start with them two come over here she has to leave the dog cat she comes back she stays here, comes back takes one $\mathrm{n}$ rabbit ...

Some parts are reduced to the extent that they are impossible to understand by someone other than the speaker. The first example shows the omission of the object after the verb take and the subject before the first verb will. The second example shows an interesting utterance in the speaker's private speech. These words (i.e., boom, boom) indicate that the participant is using a unique way of evaluating a move (e.g., taking the guy first is wrong). Indeed, this is likely a reflection of what Vygotsky (1987) discusses as smysl, or sense, that we can create in private speech in which an individual imbues a word with unique and personal, rather than normatively accepted, meaning.

The last example shows omission of the subject of the verb come twice and the verb take because the speaker already knows what the subject is and there

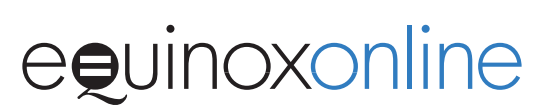


was no need to mention it for himself. As shown in the video recording of the task, the subjects omitted in these three places are girl and cat, girl and boy successively. It is worth noting that after finishing with the girl and cat, the speaker makes an abrupt shift to the boy without mentioning the shift in his speech (i.e., without giving any consideration to outside listeners). This is a further indication that the speaker is absorbed in the puzzle and his language is mostly cognitively, rather than, interactively, oriented. Moreover, this speaker left out any connecting devices (e.g., and then, after that) and his private speech was virtually reduced to indicate the moves that were performed; that is, the speaker was not concerned about producing full structures. These examples by the non-native speakers show similar condensation of language:

NNS-5) ... the girl and the boy go together, girl gets off boy comes back,, ... the boy and the rabbit go together, rabbit gets off, ...

NNS-6) ... the man can take the girl now, and take her drop her here come back, take this guy and go there $\ldots$

NNS-7) ... if I do this drop the girl back take the bunny back and switch ...

NNS-8) ... the boy takes the bunny, cross, leaves the bunny here takes the girl brings her back,

The first example indicates omission of the definite articles. Although this omission can be understood as lack of ability to use articles, this speaker uses the definite article properly in the first mention of the noun phrase and then omits it in subsequent repetitions of that noun phrase. Similar omission of articles by native-speaking children was also reported in Frawley and Lantolf (1985). The utterances were reduced to the subject and what the subject did. The second example shows how the speaker focused on the central action he performed and left out any cohesive elements; that is, he did not use connectors as would be expected if he were addressing another person (i.e. take her and then drop her here, then come back). Furthermore, although there were six actions performed, the participant only mentioned the subject once and then failed to overtly mark it during the remainder of the excerpt, which indicates that focus was on the action that was carried out. The third and fourth examples show significant reduction using the words back (representing a whole move: go back) and cross respectively to replace entire sentences.

\section{Reduced volume and/or whisper}

There were numerous examples of whisper and low voice in the discourses. In such instances, the participants were apparently addressing themselves since their speech was not sufficiently loud to be classified as social speech. In some

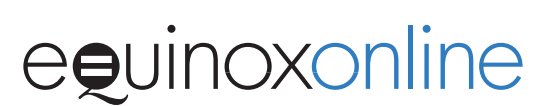


examples, when a participant speaks quietly, his/her private speech becomes unintelligible and then disappears into silence. However, the transition can be abrupt at times and the speaker may switch from normal volume directly to complete silence. The following three examples illustrate this process from the native speaker discourses:

NS-7) Ok maybe I should take xxx $[$ sigh $], \ldots$ the rabbits are still there, I just xxx, the man comes xx over and then comes back, ...

NS-8) ... in order to get her over there a person has to take her, and they can't because they ll leave their, people, I can do this right? $\underline{\text { Yah }}$...

NS-9) ... you take the girl first, xxx take this guy first boom, boom, no he can’t ...

The same feature is evident in the performance of the NNSs as shown in the following examples:

NNS-9) ... come back xxxx man and the dog goes, takes the rabbit, then the boy and

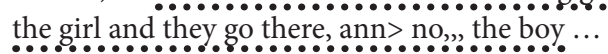

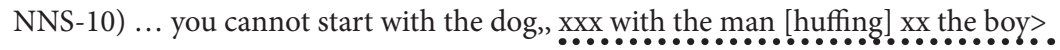
$\mathrm{x}$ the girl $>$ and drop her there, $\mathrm{xx}$ the boy will bring the girl oh the $\mathrm{b}$ the $\mathrm{g}$ boy will come back, cannot take the rabbit, oks [with a sigh], so the man ...

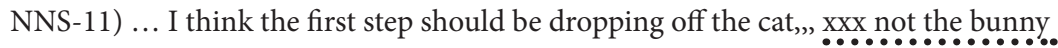
xxx xx drop the cat [laughs] no, xxx mmm, , [laughs], UHH gosh ...

In both groups' utterances whisper was very frequent; however, some participants spoke in low voice more than others, which appears to be influenced by other possible factors such as personality and the participant's belief about the need to speak audibly. What was unexpected in this regard is that one nonnative speaker worked on the problem virtually in complete silence before she gave up upon reaching the third level. This participant did not even whisper and, unfortunately, the recording did not pick up any part of her private speech, which seemed to remain subvocal.

\section{No expectation of response}

Throughout their discourses, the participants asked questions about the accuracy, possibility, etc. of their moves in solving the problem. These questions were part of their intrapersonal communication as they attempted to solve the problems. Although the participants were addressing the researcher at times, these occasions were limited and easily identifiable. In such instances, the participant spoke in a sufficiently loud volume, paused awaiting a response and there was an immediate interpersonal reply from the researcher. Making eye

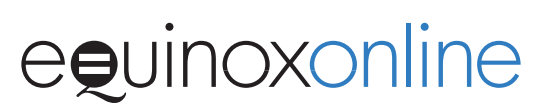


contact was another sign of interpersonal communication. In intrapersonal communication, however, the participants spoke in lower volume, did not make eye contact and did not wait for an external response. In many cases the participants audibly responded to their own questions or proposals, which indicated that the speaker was immersed in intrapersonal communication. The following illustrative examples were produced by native speakers:

NS-10) ... I've already tried this and leaves the cat, and then $>$ she takes, the boy $>$ ? No and then $>$...

NS-11) ... there's no way you have to start with these two, or you start with these two? Same thing ok we start with the dog ...

NS-12) ... so he can't go at all,, how it worked the first time?, so that's not it, ok I give up $\mathrm{xx} \underline{\mathrm{ok}} \ldots$

NS-13) ... maybe if they're last wait a minute , will this work? Did I try that already? No can't do that or can I? , no can't do that son of a gun ...

These examples show that the speakers were immersed in intrapersonal communication exploring the possibilities they had and apparently were not waiting for anyone to respond to their questions. As these examples demonstrate, there is not a significant period of silence after the questions, which diminishes the likelihood that the questions were intended for anyone other than the self. Moreover, in the second and third examples the speakers were murmuring in low voice when they asked the questions, which is another indication that they were talking to themselves. The final excerpt (NS-13) is somewhat different because the speaker produced a cluster of self-directed inquires and responses.

The following examples are taken from the NNSs discourses, and manifest the same behaviour as in the case of the NSs:

NNS-12) ... he comes back, actually no, xxx and then $>$ what ... > ,....... [tapping fingers

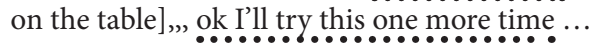

NNS-13) ... well > aaa what should I do ok so $>$ they should be together so like this, but if ...

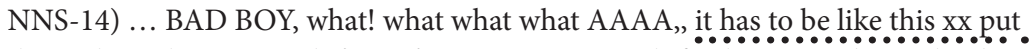
down the girl,, Xx Xxx, ah focus focus AAH it is so difficult,, mm it has to be the the cat,, cannot be these ...

NNS-15) ... okay good so what we do?, we do, we go the boy and rabbit ...

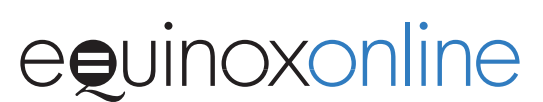


The speakers here were not expecting anyone to respond except themselves. As the examples show, they answer their own questions immediately and/or they speak in a low voice, which means that the inquiry was not directed to a social interlocutor. These self-directed inquiries have self-regulatory functions.

\section{Directions to the self}

When participants explored the options available as they were working on the problem, they mediated themselves to gain control and to try out the different options by instructing and guiding themselves. It is worth noting that this characteristic is similar to what happens in social interactions when one individual guides and provides mediation to another person. The following are examples from the NNSs' discourse:

NS-14) ... the boy goes back and picks up a rabbit, oh but then the rabbit can't be alone with the girl, so then maybe ...

NS-15) ... the rabbit near the girl so I'll take> the rabbit, no I can't do that cause the rabbit and the dog can't be left alone...

NS-16) ... there's no way you can leave so you have to take the girl, take the girl, unless you take a rabbit but if you leave a rabbit you can't drive back ...

NS-17) ... you have to start with these two, you can't start with these ...

Each example demonstrates how the speakers interrupted themselves to critique their performance and give directions in order to make better decisions. These excerpts show the participants making corrections in the reasoning process (NS-14 and NS-15) and giving instructions on what could and what could not be done (NS-16 and NS-17).

The following are similar examples produced by the NNSs:

NNS-16) ... and drop her there, $\mathrm{xx}$ the boy will bring the girl oh the $\mathrm{b}$ the $\mathrm{g}$ boy will come back, cannot take the rabbit,, ok> [with a sigh], so the man cannot take the rabbit because the dog will be with him, ...

NNS-17) ... ok so we drop these here the boy comes back $>$ he jumps out $>$ you cannot leave $\mathrm{xxx}, \mathrm{mm}$ yah no, the girl takes $>$ the boy takes the cat no he cannot, the girl takes the dog he she cannot...

NNS-18) ... they get off, and then $>$ AND THEN $>$ they cannot go so $>$ the boy transfers another rabbit to the other side, ...

NNS-19) ... so we cannot leave the bunny down but I can take the girl and then>, I can either throw down the girl take the bunny or throw down the boy, no cannot do the other way ...

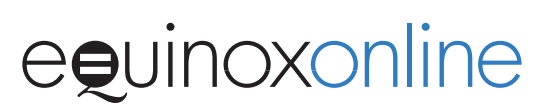


The NNSs' examples are similar to those produced by the NSs. What is remarkable is that it may be difficult to realize that only one person is talking without understanding the background context. The resemblance of the speakers' discourses to social speech is also demonstrated in the following section.

\section{Dialogue with the self}

A noticeable feature in the discourses was the frequency of dialogue with the self. Although these were not perfectly developed conversations, they were easily discernible as dialogues. The dialogues functioned as internal negotiations in order to arrive at the best procedure to proceed in solving the problem. Such intrapersonal dialogues represent a clear manifestation of the use of language as a cognitive tool. Each speaker partnered with him/herself (the social self, Vocate, 1994), in order to have the opportunity to argue back and forth and work out appropriate moves. The following examples are taken from the NSs' discourses:

NS-18) ... xxxx again and then the man comes back,, no because she can't be left with him and he can't be that so ...

NS-19) ... the b, ,, the man brings the dog across the river and then goes back, but he can't be separate from them, and the rabbit can't drive the boat back, so I think that's how it starts,, if the oops if the, the boy can't bring one rabbit because there's still a rabbit left behind with the girl, so>, can the boy bring the girl? Yes sure ...

NS-20) ... IT IS DOABLE? Yah sure ok alright alright it is doable alright, alright so, say we $>$ we can't leave the kid with xx ok so that means,, you can't leave $m$ like that ok so so there's no way you have to start with these two, or you start with these two? Same thing ok we start with the dog and the man ...

In the first example, the participant rejected a move and justified why it was not appropriate. The second example highlights an opposing opinion that emerged (but he can't be separate from them, and the rabbit can't ...) in the middle of the speaker's reasoning, which led to some adaptation of a particular procedure (so I think that's ...). In the third example, the speaker started with a question to the researcher expressing his scepticism about the possibility of actually solving the problem. After realizing it was doable, the speaker told himself the new piece of information, seemingly, in an effort to convince and urge himself to work harder. Immediately, the hard work started with intense instruction to the self. In this excerpt, the social part of the speaker (i.e., 'Me') explains the restrictions and possibilities and then both selves 'I' and 'Me' decide on what to do accordingly as indicated by the shift to the pronoun 'we'. Vocate (1994: 12) explains this phenomenon stating that '.. the "I" makes choices, and

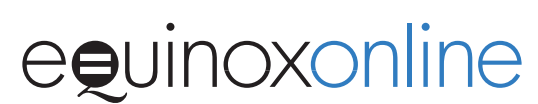


the interpretive, critical process that follows from the "Me" allows us to adapt ourselves mentally, physically or both before we think or act further.'

The NNSs produced similar utterances as illustrated below:

NNS-20) ... ok the boy transfers the girl to the other side, he comes back, actually. no, $x x x$ and $\ddot{0}$ en $>$ what $>>$, no,, ...

NNS-21) ... oh then the girl should go first maybe,, wait no [laughs] $\mathrm{xxx}$ if the girl goes, then $>>$, and then $>$..........

NNS-22) $\ldots$ and then $>$ what $>$ ? , and then $>$ ahh no no no no no no no no [emotional]

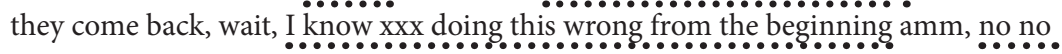
let me $\mathrm{xxxx}$ one more time ...

As these examples show, the non-native speakers produced short dialogues very similar to those found in the native speakers' private speech. In the first example, the speaker (the 'I') suggested a move and then the social interlocutor (Me) evaluated that move as useless, which led to confusion and an appeal for clarification using the interrogative what. In the second excerpt, the speaker (the 'I') proposes a move (should go first maybe) and then the 'Me' suggests reconsideration of the action (wait no). The dialogue is intense in the third excerpt and it reminds us of a heated interpersonal argument. In this dialogue, the social part of the self (Me) was trying to keep track of the moves and asks (what $>$ ?) and then the social aspect appears again as Me rejected the proposed move vehemently (ahh no no no no no). The personal aspect of the speaker (I) makes another suggestion (... they come back,) after which the social self asks the speaker to slow down (... wait,) possibly to allow time for evaluation. The dialogue is finalized with a request by the social self to start over (... one more time) for further evaluation.

It is worth mentioning that most of these intrapersonal dialogues are choppy and fragmented; yet, this is a well-known feature of private speech and provides another clue that the dialogues were exclusively intrapersonal. Additionally, these intrapersonal dialogues were mostly produced in low volume, which emphasizes their self-regulatory function.

\section{Others (sounds, swearing, unintelligible)}

This category includes other features such as swearing, and in some cases the utterances were unintelligible to a non-participant observer. Examples of cursing and unintelligible muttering or sounds were present in both the native and non-native speakers' discourses. Expletives, which served as a way of letting out the participant's frustration, were produced when the speaker was having difficulty with some part of the problem. Unintelligible utterances were

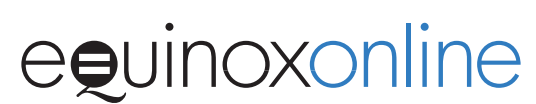


frequent in most of the discourses and this feature is another indication that the participants were talking to no one other than themselves. The following examples are from the NSs' private speech:

NS-21) ... he comes back and brings over $>>$ the boy $>$ but the girl is there oh the girl is with the rabbits damn it emm, ok xx the girl ... so maybe the man will bring the rabbit the dog oh yah damn it..... [sighs],, the b,,, the man ...

NS-22) ... I'm > going > to take, the >, I'm going to take, ah darn it, [laughs] I DON'T KNOW WHY THIS IS SO MUCH HÄDER ...

NS-23) ... if I leave the rabbit here she's gonna tease it SON OF A GUN alright so instead ... she can't be in the boat with the rabbit cause she's gonna tease it that little... bitch hahaha ammm, SON OF A GUN ...

NS-24) ... if she gets off and he sails this is crazy WAIT A MINUTE WAIT A MINUTE AHHH son of a bitch, wait a minute ... oh son of a gun so we got to get rid of her, ha we can't do that what the hell, ... yah damn it......... can't quit though ...

It is noteworthy that some participants produced fewer expletives than others and some had less unintelligible speech. Some examples of muttering were also present in the excerpts. Recurring whisper in the participants' discourse is another unmistakable clue that what the speakers said was mainly intended for cognitive mediation.

Again, the NNSs exhibited similar behaviour.

NNS-23) ... come back, wait, I know xxx doing this wrong from the beginning amm, no no let me xxxx one more time [tapping fingers on the table], the man ...

NNS-24) ... s... you cannot start with the dog, xxx. with the man [huffing] xx the boy $>\mathrm{x}$ the girl $>$ and drop her there, $\mathrm{xx}$ the boy $\cdots$

NNS-25) ... well Xxx Xxx ohh mm, the girl then well> yah then, the boy, bunny, but now you left the other bunny with the girl AHHH [laughs] ohh shoot, [laughs] IS IT POSSIBLE? ...

NNS-26) ... dropping off the cat,,, xxx not the bunny xxx xx drop the cat [laughs]

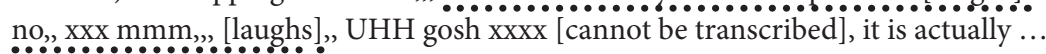

NNS-27 ... so the girl goes over there leaves the cat comes back, getsss xxx, boy goes across , khhh leaves the girl there, n he comes back ,, [tapping finger on table] Xxx. up takes one bunny across .... ahum ,, $\mathrm{xxx}$ xx $[$ huffing $]$, so $>$ are these two items ....

NNS-28) ... and then these two go together, xxx the girl will be back, ahhh,

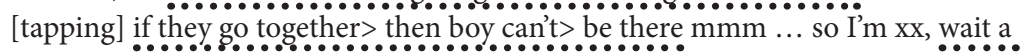
minute what the hell,,... 
As the examples show, the speakers sometimes use a very soft unintelligible voice but for a relatively short period of time, possibly because they need to speak louder in order to gain control over the task. Vygotsky (1978) argues that the amount and volume of private speech increase with task complexity. It is noticeable that swearing was used more by some participants than others which might be an idiosyncratic issue. For instance, NNS-24 and NS-24 produced virtually no expletives, while NS-23 produced 15 such expressions. Although using expletives may be idiosyncratic, struggling with the task should have intensified it; compared to other participants NS-23 had a hard time dealing with the problem and made very little progress in resolving it.

Another feature that was evident in some examples is that the speakers were trying to hide the fact that they were using expletives, which was indicated by their whispering quietly to themselves. Expletives along with huffing (NNS-24 and -27), sighs (NS-21; NNS-25 and -26), exclamations (NS-22; NNS-25), tapping (NNS-23 and -28) and unintelligible speech emerged because of lack of control over the task. They serve as an indication that the speaker was cognitively engaged in solving the problem and having difficulty at the same time.

\section{Reversion to the L1}

The presence or absence of the L1 in the non-native speakers' private speech is an important factor in assessing the effectiveness of using the non-native language in mediating cognitive functioning. Outwardly, the non-native speakers' L1 were not detected in the discourses. However, some participants became silent on some occasions as they worked on the problem. This left some doubt as to whether or not those participants resorted to the L1 at those times. It is worth noting that although the instructions and characters in the activity were presented in the L2, the participants were not instructed to exclusively use the L2.

Given the importance of this factor, the researcher followed up each session with a verbal question directed to the participant on whether he/she used the native language at some point as he/she worked on the problem-solving activity. None of the non-native speakers reported using the L1 in the silent portions of their reasoning. Two speakers, however, stated that they would possibly resort to their native languages if the instructions and characters were not presented in the L2. This is in need of further investigation and a good target for future research.

\section{Progress in solving the task}

With regard to the progress each participant achieved in solving the different problem levels, the non-native speakers were generally better than the native speakers. Three non-native speakers succeeded in solving all three levels of

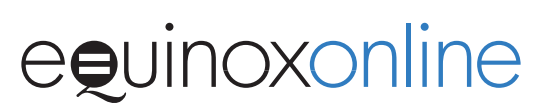


the problem and the other four completed the second level. As for the native speakers, none of them progressed beyond the second level of difficulty. In fact, only one native speaker finished the second level, while the other three gave up before solving the full problem set. We need to keep in mind, however, that those participants who did not solve all levels of the problem may not have put the same effort into the task as others. NNS3 and NS4, for instance, spent only eight minutes on the problem before they gave up without finishing it. While NNS2, who was more determined and took the challenge presented in the problem seriously, spent over half an hour working before completing all three levels.

It is worth highlighting that a host of non-linguistic factors (e.g., state of mind, lack of interest, setting, and level of distraction) could have influenced a participant's ability to solve the problem set. The most significant result, however, is that using the L2 did not prevent the non-native speakers from achieving success. This was specifically evident with regard to NNS1 and NNS4, who finished the three levels in a relatively short span of time (12 minutes and 16 minutes, respectively). Appendix 2 reports the levels passed and time spent in the task for each participant.

\section{Discussion}

The features of the discourses made it clear whether or not the participants were talking to themselves. First of all, most of the discourses are largely incomprehensible to a third-party listener because the utterances were not fully externalized. The participants did not need to fully externalize their speech because it was for the self. For the same reason, they did not have to speak loudly, hence, they were frequently muttering to themselves. The discourses were remarkably full of curtailed, condensed and unintelligible fragments because, unlike in social speech when two or more people are talking to each other, 'the self is a highly sympathetic and understanding listener' (Berk, 1992: 21).

All the features that were highlighted in the problem-solving activity consistently indicate that the participants were using the language to assist their thinking. There were a few instances in which the participants addressed the researcher; these instances, however, were easily identifiable. Expressions that were intended for interpersonal reasons, like asking a question about the problem, were usually accompanied by immediate response from the researcher. Although the participants asked many questions that sounded interpersonal, the use of such inquiries was primarily for cognitive purposes. As it was reported in the results section, in such instances, the speakers either responded to their inquiries right away or shifted to something else. The way the speakers proceeded makes it clear that they were not expecting answers

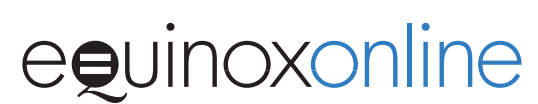


from the researcher. Another indication that the speakers were not expecting responses from anyone is that they were sometimes murmuring in quiet voices.

Dialoguing with the self was another frequent feature in the discourses. In fact, the process of solving the problem was a continuous dialogue with the self, but because private speech is condensed and fragmented, the dialogue was not always totally discernible. The presence of this phenomenon in private speech is supported by Vygotskian and Bakhtinian views on inner voice. Vygotsky (1978) believes that private speech, although functioning as a cognitive tool, has social features. Likewise, Bakhtin '... argued that inner speech is best understood as dialogue; a continuous two-way interaction between the subjective and the social' (Morris, 1994: 49). Vocate (1994) provides a highly focused explanation of this aspect of private speech as she states that '... as with social talk, self-talk is dialogic, but instead of an "I" who is talking to a "You", private speech entails an "I" that makes choices on what to talk about and a "Me" that interprets and critiques these choices' (Kozulin et al., 2003: 351). Vocate clarifies how the social 'partner' in personal dialogue comes about as she states that:

the interaction of the individual ['I'] and societal components of the self ['Me'] ... entails an interdependency between the individual and the environment because the 'Me' originates in the attitudes of specific others and the community and then evolves into a new synthesis of self as it responds to the activities and views of the 'I'. (1994:

14)

Thus, the NNSs showed evidence that they may have indeed developed the capacity to dialogue with the self through their new language as a result having been through formal instruction as well as immersion experiences in the native-speaking community.

The L1 was not detected in the speech of any of the NNS participants in the present study. All of them sustained their thinking in the second language throughout the activity. At the same time, they made progress in solving the problem with some of them succeeding at solving all three levels of difficulty. Unlike results from previous studies that used mathematical problems (Centeno-Cortés and Jiménez-Jiménez, 2004; Cohen, 1994), avoiding the L1 in the present study supports the argument that speakers may resort to the language of acquisition in more specialized contexts - as when working on math problems. Although, this conclusion is in need of more investigation.

Working on the same problem-solving tasks that were used in CentenoCortés and Jiménez-Jiménez (2004), the bilingual speakers in JiménezJiménez (2015) produced private speech mostly in the language in which the problems were presented, which echoes statements by the two participants in

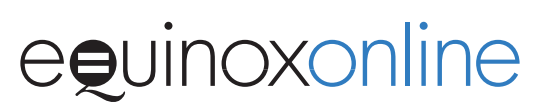


the present study who observed that they would have possibly resorted to their native languages if the instructions and characters had not been presented in the L2. Yet, as stated earlier, we should keep in mind that the language of acquisition of those particular areas of knowledge on which the participants in Jiménez-Jiménez (2015) were tested could have had a greater influence on the choice of language; although, the influence of the language in which a problem is framed seems to be significant and also calls for more research.

The fact that about half of the non-native speakers managed to solve all the levels in the puzzle task - while at the same time sustaining their L2 - is an additional piece of evidence that the non-native language functioned as an effective cognitive tool. Considering the poor performance of the native speakers in comparison to the L2 speakers, a possible area for future research is to look into whether being a bilingual give non-native speakers an advantage over native speakers in similar general cognitive tasks.

One important issue that has not been robustly addressed in the literature is that we cannot use a speaker's poor performance in a given task to conclude that his/her language did not successfully mediate his/her thinking. Lack of control over a task (i.e., object-regulation) cannot be conclusively interpreted as an indication that a speaker's language is not mediating his/her thinking. Many factors can hinder the process of solving a problem; thus, we cannot attribute failure in solving a cognitive problem solely to a weakness in language mediation. This is because lack of control can result from many non-language related sources - as was most likely the case with some native speakers in the present study. On the other hand, self-regulation (i.e., success in performing a cognitive task) can be taken as an indication that the speaker is using the language in his/her thinking and is therefore not an obstacle in solving the problem at hand.

\section{Conclusion}

As the analysis indicated, there was evidence that the L2 speakers who participated in this study mediated their thinking through the L2. All the L2 speakers were cognitively immersed in negotiating and reasoning in the L2 as they worked through the problem-solving task. Moreover, their private speech production was persistent throughout their performance and the native language did not appear overtly in their utterances, which means that the L2 was the only language the participants used in solving the problem. Additionally, most L2 speakers made considerable progress in solving the levels in the puzzle and is another indication that the L2 worked successfully to assist the speakers' thinking. Needless to say, body language is important to clearly differentiate social speech from private speech in such a context when the possibility

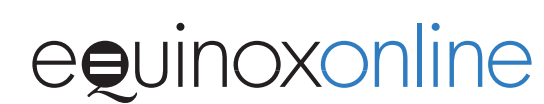


to produce either is present as it was the case in the present study; thus, any future research should include video recording.

Extensive formal and informal acquisition experiences can make a nonnative language a cognitive tool similar to the native language. Yet, different speakers may need different amounts of exposure to start utilizing the nonnative language as a mediational tool for cognitive functioning. Although it cannot be confirmed on the basis of the present study, it likely that the L2 speakers with more extensive and intensive periods of exposure to the L2 performed better than their counterparts with less exposure. This possibility of course requires confirmation and is a possible area of future research.

When conducting research on the cognitive role of L2 in problem solving among bilingual or multilingual speakers, researchers should keep in mind the language of acquisition of the specific type of knowledge on which the participants are tested. This factor could be the reason why the thinking process of some speakers is influenced by their first language (as in previous studies like Centeno-Cortés and Jiménez-Jiménez, 2004; Jiménez-Jiménez, 2015). This is another area that calls for further research.

\section{About the author}

Mostafa M. Garbaj is an assistant professor of linguistics at Asmarya University, Department of English, Libya. He holds a $\mathrm{PhD}$ in Foreign and Second Language Education from SUNY-Buffalo. His research interests include sociocultural theory and second language acquisition.

\section{References}

Ahmed, M. K. (1994). Speaking as cognitive regulation: A Vygotskian perspective on dialogic communication. In J. P. Lantolf and G. Appel (Eds), Vygotskian Approaches to Second Language Research, 157-172. Norwood, NJ: Ablex.

Berk, L. E. (1992). Children's private speech: An overview of theory and the status of research. In L. E. Berk and R. M. Diaz (Eds), Private Speech: From Social Interaction to Self-regulation, 17-53. Hillsdale, NJ: Lawrence Erlbaum.

Centeno-Cortés, B. and Jimenéz-Jimenéz, A. (2004). Problem-solving tasks in a foreign language: The importance of the L1 in private verbal thinking. International Journal of Applied Linguistics 14: 7-35. https://doi.org/10.1111/j.1473-4192.2004.00052.x

Cohen, Andrew D. (1994). The language used to perform cognitive operations during full immersion math tasks. Language Testing 11 (2): 171-195. https://doi.org/10.1177/ 026553229401100205

Frawley, W. and Lantolf, J. P. (1985). Second language discourse: A Vygotskyan perspective. Applied Linguistics, 6: 19-44. https://doi.org/10.1093/applin/6.1.19

Jiménez-Jiménez, A. (2015). Private speech during problem-solving activities in bilin-

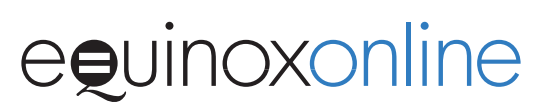


gual speakers. International Journal of Bilingualism, 19 (3): 259-281. https://doi.org/10. $1177 / 1367006913509902$

Kozulin, A., Gindis, B., Ageyev, V. S. and Miller, S. M. (2003). Vygotsky's Educational Theory in Cultural Context. New York: Cambridge University Press. https://doi.org/10.1017/ CBO9780511840975

Lantolf, J. P. and Appel, G. (1994). Vygotskian Approaches to Second Language Research. Norwood, NJ: Ablex.

Lantolf, J. P., DiCamilla, F. J. and Ahmed, M. (1997). The cognitive function of linguistic performance: Tense/aspect use by L1 and L2 speakers. Language Sciences, 19: 153-165. https://doi.org/10.1016/S0388-0001(96)00003-4

Lantolf, J. P. and Frawley, W. (1994). Second language performance and Vygotskyan psycholinguistics: Implications for L2 instruction. In J. P. Lantolf and G. Appel (Eds), Vygotskian Approaches to Second Language Research, 117-134. Norwood, NJ: Ablex.

Lantolf, J. P. and Thorne, S.L. (2006). Sociocultural Theory and the Genesis of Second Language Development. Oxford: Oxford University Press.

McCafferty, S. G. (1994). The use of private speech by adult ESL learners at different levels of proficiency. In J. P. Lantolf and G. Appel (Eds), Vygotskian Approaches to Second Language Research, 117-134. Norwood, NJ: Ablex.

Morris, P. (1994). The Bakhtin Reader: Selected Writings of Bakhtin, Medvedev, Voloshinov. London: Arnold.

Piaget, J. (1959). The Language and Thought of the Child. New York: Harcourt, Brace.

Smart-kit: River crossing puzzle (2012). Accessed 18 May 2013 at http://smart-kit.com/ s888/river-crossing-puzzle-hard/

Spelke, S. and Tsivkin, S. (2001) Language and number: A bilingual training study. Cognition, 78: 45-88. https://doi.org/10.1016/S0010-0277(00)00108-6

Ushakova, T. N. (1994). Inner speech and second language acquisition: An experimental theoretical approach. In J. P. Lantolf and G. Appel (Eds), Vygotskian Approaches to Second Language Research, 135-156. Norwood, NJ: Ablex.

Vocate, D. R. (Ed.). (1994). Intrapersonal Communication: Different Voices, Different Minds. Hillsdale, NJ: Erlbaum.

Vygotsky, L. S. (1986). Thought and Language (A. Kozulin, Trans.). Cambridge, MA: MIT Press.

Vygotsky, L. S. (1978). Mind in Society. Cambridge, MA: Harvard University Press.

Vygotsky, L. S. (1987). The Collected Works of L. S. Vygotsky: Vol.1, Problems of General Psychology. Including the Volume Thinking and Speech. (N. Minick, Trans.). New York: Plenum. 


\section{Appendix 1. Data transcription key}

\begin{tabular}{|l|l|}
\hline Code & Description \\
\hline$>>$ & prolonged utterance/syllable \\
\hline, & Short pause \\
\hline$"$ & longer pause \\
\hline [] & information/description added by researcher \\
\hline Solid underline & researcher's speech \\
\hline UPPERCASE & loud voice \\
\hline Lowercase & normal voice \\
\hline Dotted underline & low voice \\
\hline xxx & unintelligible \\
\hline
\end{tabular}

\section{Appendix 2. Additional details about the participants}

\begin{tabular}{|l|c|l|l|l|c|c|c|}
\hline Participant & Age & Gender & $\begin{array}{c}\text { Native } \\
\text { language }\end{array}$ & $\begin{array}{c}\text { Exposure } \\
\text { to the L2 }\end{array}$ & $\begin{array}{c}\text { Interview } \\
\text { score }\end{array}$ & $\begin{array}{c}\text { Level } \\
\text { solved }\end{array}$ & $\begin{array}{c}\text { Task } \\
\text { time }\end{array}$ \\
\hline NNS1 & 45 & Male & Arabic & 15 years & 9 & 3 & $12: 00$ \\
\hline NNS2 & 40 & Male & Arabic & 21 years & 9.5 & 3 & $32: 00$ \\
\hline NNS3 & 44 & Male & Urdu & 13 years & 9.5 & 2 & $8: 00$ \\
\hline NNS4 & 27 & Male & Chinese & 5 years & 8.5 & 3 & $16: 00$ \\
\hline NNS5 & 36 & Female & Korean & 5 years & 8 & 2 & $11: 00$ \\
\hline NNS6 & 30 & Female & Japanese & 4 years & 8 & 2 & $25: 00$ \\
\hline NNS7 & 24 & Female & Chinese & 4 years & 7.5 & 2 & $27: 00$ \\
\hline NS1 & 25 & Female & English & NA & NA & 2 & $16: 00$ \\
\hline NS2 & 28 & Female & English & NA & NA & 1 & $15: 00$ \\
\hline NS3 & 43 & Male & English & NA & NA & 1 & $26: 00$ \\
\hline NS4 & 28 & Male & English & NA & NA & 1 & $8: 00$ \\
\hline
\end{tabular}

